\title{
Unmarked Gene Editing in Clavibacter michiganensis Using CRISPR/Cas9 and 5-Fluorocytosine Counterselection
}

\author{
Xing Chen, ${ }^{1}$ Qing Tan, ${ }^{1}$ Qingyang Lyu, ${ }^{1,2}$ Chengxuan $\mathrm{Yu},{ }^{1} \mathrm{Na}$ Jiang, ${ }^{1}$ Jianqiang $\mathrm{Li},{ }^{1}$ and Laixin Luo ${ }^{1, \dagger}$ \\ ${ }^{1}$ Department of Plant Pathology and MOA Key Laboratory of Pest Monitoring and Green Management, College of Plant \\ Protection, Beijing Key Laboratory of Seed Disease Testing and Control, China Agricultural University; Beijing, P. R. China \\ ${ }^{2}$ CAS Key Laboratory of Environmental and Applied Microbiology, Environmental Microbiology Key Laboratory of Sichuan \\ Province, Chengdu Institute of Biology, Chinese Academy of Sciences, Chengdu, P. R. China
}

Accepted 19 September 2021.

\begin{abstract}
Plant-pathogenic bacteria in the genus Clavibacter are important quarantine species that cause considerable economic loss worldwide. The development of effective gene editing techniques and additional selectable markers is essential to expedite gene functional analysis in this important Gram-positive genus. The current study details a highly efficient unmarked CRISPR/Cas9-mediated gene editing system in Clavibacter michiganensis, which couples the expression of cas9 and single-guide RNA with homologydirected repair templates and the negative selectable marker $\operatorname{codA}:$ :upp within a single plasmid. Initial experiments indicated that CRISPR/Cas9-mediated transformation could be utilized for both site-directed mutagenesis, in which an $A$ to $G$ point mutation was introduced at the 128th nucleotide of the $C$. michiganensis $r p s L$ gene to generate a streptomycin-resistant mutant, and complete gene knockout, in which the deletion of the $C$. michiganensis celA or katA genes resulted in transformants that lacked cellulase and catalase activity, respectively. In subsequent experiments, the introduction of the $\operatorname{codA}::$ upp cassette into the transformation vector facilitated the counterselection of unmarked transformants by incubation in the absence of the selective antibiotic, followed by plating on M9 agar containing 5-fluorocytosine at $100 \mu \mathrm{g} / \mathrm{ml}$, in which an unmarked $\mathrm{katA}$ mutant lacking the transformation vector was recovered. Compared with conventional homologous recombination, the unmarked CRISPR/ Cas9-mediated system was more useful and convenient because it allowed the template plasmid to be reused repeatedly to facilitate the editing of multiple genes, which constitutes a major advancement that could revolutionize research into $C$. michiganensis and other Clavibacter spp.
\end{abstract}

Keywords: 5-fluorocytosine, bacterial pathogenesis, Clavibacter michiganensis, CRISPR/Cas9, homologous recombination

\footnotetext{
${ }^{\dagger}$ Corresponding author: L. Luo; luolaixin@cau.edu.cn
}

Funding: The National Key Research and Development Program of China (number 2017YFD0201601).

*The $\boldsymbol{e}$-Xtra logo stands for "electronic extra" and indicates that a supplementary figure and supplementary table are published online.

The author(s) declare no conflict of interest.

(c) (1) $(2)($ Copyright $(\odot) 2021$ The Author(s). This is an open access article distributed under the CC BY-NC-ND 4.0 International license.
Clavibacter is a genus of Gram-positive plant-pathogenic bacteria that are noted for their high (65 to 75\%) GC content (Davis et al. 1984; Whitman et al. 2012). The damage caused by Clavibacter pathogens results in significant losses to crop production throughout the world, and Clavibacter michiganensis, the causal agent of bacterial canker of tomato, has long been considered a quarantine bacterium, the spread of which must be controlled to prevent dramatic economic losses to global tomato production. However, research regarding the pathogenicity of $C$. michiganensis has been somewhat limited, and has mainly focused on the cell-wall-degrading enzymes and serine proteases associated with the development of wilt and canker symptoms (Chalupowicz et al. 2017; Dreier et al. 1997; Jahr et al. 2000) and, although several virulence factors have been identified based on single-gene exploration or whole-genome sequence analyses, molecular investigation of the host-pathogen interaction has been hampered by the absence of convenient techniques for the genetic manipulation of $C$. michiganensis.

A major breakthrough in the transformation of $C$. michiganensis came in 1991 with development of the pDM100 cloning vector (Meletzus and Eichenlaub 1991). The subsequent development of a mutagenesis system based on antibiotic resistance transposons in combination with an improved electroporation protocol (Kirchner et al. 2001) provided greater opportunities for gene functional analysis in C. michiganensis. For example, knockout and complementation studies of $c e l A, \operatorname{chp} C$, and $\operatorname{chp} G$ were conducted using homologous recombination via suicide plasmids, which confirmed that cell-wall-degrading enzymes and serine proteases play an important role in the development of wilt and canker symptoms (Hwang et al. 2019; Jahr et al. 2000; Stork et al. 2008), while $p b p C$, an enzyme involved in peptidoglycan assembly, was found to be associated with stress resistance (Chen et al. 2021). However, the limited availability of selectable markers has proven to be an obstacle in the construction of multigene knockout mutants, resulting in a stagnation of research focused on the interaction of different pathogenesis-related genes. Therefore, the development of a novel molecular technique to facilitate the routine production of multigene mutants is essential to further understanding of the C. michiganensis infection process.

The discovery of the clustered regularly interspaced short palindromic repeats (CRISPR)/CRISPR-associated (Cas) bacterial immune system, which provides protection against exogenous nucleic acids and bacteriophage invasion (Garneau et al. 2010; Horvath and Barrangou 2010; Mohanraju et al. 2016), was quickly recognized as an opportunity to greatly improve strategies for genetic manipulation in all manner of circumstances. The 
CRISPR/Cas-mediated defense system involves three stages: adaption, in which foreign DNA (protospacers) are acquired and incorporated into the CRISPR locus, a portion of the bacterial genome that acts as a repository to recognize the foreign DNA; expression, which involves transcription of the CRISPR RNA (crRNA) that acts as a guide to identify invading nucleic acids; and interference, in which the Cas9-crRNA complex interacts with foreign DNA, resulting in cleavage of the target DNA by the Cas9 endonuclease (Garneau et al. 2010; Marraffini 2015; Mohanraju et al. 2016; van der Oost et al. 2009). The key elements in the CRISPR/Cas system that allows it to be exploited for genetic manipulation are the protospacer adjacent motifs (PAMs) that initially select the protospacer sequences, because they allow artificial or guide RNA (gRNA) to be created that can target Cas9 to any site in the genome (Jinek et al. 2012; Mojica et al. 2009). The CRISPR/Cas system is extremely versatile and can be applied in both prokaryotes such as Escherichia coli (Jiang et al. 2015; Zhao et al. 2016), Streptomyces spp. (Chen et al. 2017; Huang et al. 2015), and Bacillus spp. (Li et al. 2018; K. Zhang et al. 2016) and in eukaryotes such as the fungus Phytophthora infestans (Ah-Fong et al. 2021), as well as higher plants (Zong et al. 2017) and animal cells (Shalem et al. 2014). However, to date, there have been no reports of CRISPR/Cas being used in Clavibacter spp., which likely results from the combination of the high GC content of the Clavibacter genome as well as the lack of suitable selectable markers and expression vectors for the Cas 9 and gRNA components.

Although antibiotic resistance genes provide a very convenient method for selecting successful transformation events, they can limit the number of times a particular cell line can be altered, because each new transformation requires a different selectable marker. However, the use of negative selectable markers for counterselection presents the opportunity to sequentially knockout multiple genes using an unmarked gene strategy. The codA::upp cassette has been developed for counterselection in Rhodococcus equi (van der Geize et al. 2008), which contains the E. coli cytosine deaminase and uracil phosphoribosyltransferase genes ( $\operatorname{cod} A$ and $u p p$, respectively) that convert the innocuous cytosine analog, 5-fluorocytosine (5-FC), first into 5-fluorouracil and then into 5-fluorouridine monophosphate, an extremely toxic compound that irreversibly inhibits thymidylate synthase, resulting in the inhibition of DNA and RNA synthesis and, ultimately, cell death (Andersen et al. 1989; Daher et al. 1990; Danielsen et al. 1992; Greco and Dachs 2001; Hughes et al. 2005; Loyse et al. 2013; Rezzoagli et al. 2018; van der Geize et al. 2008; Xing et al. 2009).

To date, the transformation of Clavibacter spp. has depended on techniques that utilize homologous recombination, which has a low transformation efficiency and results in genetic "scars" resulting from the marker genes that confer resistance to the antibiotics gentamycin $(\mathrm{Gm})$ or chloramphenicol (Jahr et al. 2000; Stork et al. 2008). Therefore, the objective of the current study was to develop a novel gene-editing strategy for Clavibacter based on CRISPR/ Cas9-mediated transformation and counterselection using the $\operatorname{codA::upp~cassette.~It~was~hoped~that~such~a~system~would~greatly~}$ increase the efficiency of Clavibacter transformation as well establish a system for unmarked gene editing that would facilitate the silencing of multiple genes in combination. Such a breakthrough would undoubtedly result in rapid progress in Clavibacter research and lead to a much greater understanding of the host-pathogen interaction of these important plant-pathogenic bacteria.

\section{RESULTS}

Cas9 and single-guide RNA adaption for use in C. michiganensis.

Preliminary investigation of the CRISPR database indicated that the $C$. michiganensis genome possessed no endogenous
CRISPR system (Grissa et al. 2007a and b, 2008) and, therefore, that a foreign CRISPR/Cas9 system could be introduced to perform gene editing. Further analysis using the Codon Usage Database revealed that the $\mathrm{GC}$ content of the $C$. michiganensis genome and its codon usage was similar to that of Streptomyces coelicolor, which was a strong indicator that the chimeric single-guide RNA (sgRNA) and codon-optimized cas9 system developed for gene editing in S. coelicolor may also be effective in C. michiganensis, although further investigation was required to confirm whether the tipA and J23119 promoters used would be capable of driving expression in Clavibacter spp. Experiments interchanging the tipA and J23119 promoters for the native pcmx promoter of the Corynebacterium striatum antibiotic resistance gene $c m x$, which was known to confer chloramphenicol resistance in Clavibacter michiganensis, revealed that only the pcmx and $\mathrm{J} 23119$ promoters were functional in $C$. michiganensis, because transformants carrying the pHN216pcmx-cmx and pHN216J23119-cmx could be recovered on Luria-Bertani (LB) agar containing chloramphenicol at $10 \mu \mathrm{g} / \mathrm{ml}$, while none could be recovered with pHN216tipA-cmx (Fig. 1). Consequently, the $\mathrm{J} 23119$ promoter from the $S$. coelicolor CRISPR/Cas9 system was retained for the transcription of targetspecific sgRNA in $C$. michiganensis, while the pcmx promoter was selected for the expression of cas9.

\section{CRISPR/Cas9-mediated site-directed mutagenesis of rps $L$ in $C$. michiganensis.}

Having established suitable promoters for CRISPR/Cas9-mediated transformation in $C$. michiganensis, a gene-editing plasmid was developed to test whether the system could be used for sitedirected mutagenesis. The $C$. michiganensis ribosomal protein S12 was selected as the target for the transformation because a conserved mutation (A to $\mathrm{G}$ at the 128th nucleotide) in the rpsL gene was known to confer streptomycin (Str) resistance in a range of plant-pathogenic bacteria, including $C$. michiganensis (Lyu et al. 2019; McManus et al. 2002; Zhang et al. 2011). The transformation vector pHN216-rpsL128 (Fig. 2A), which utilized the pHN216 E. coli-C. michiganensis shuttle vector as a backbone, included four components: a neomycin (Neo)-selectable marker, Cas9 under the control of the pcmx promoter, 500 bp upstream and downstream regions of the $C$. michiganensis rpsL gene (which included the $A$ to $G$ point mutation), and a modified sgRNA scaffold designed to be a sequence in close proximity to the 128th nucleotide but which had an altered PAM sequence and a nonsense altered sequence to eliminate the BlpI restriction site, all under the control of the $\mathrm{J} 23119$ promoter (Fig. 2B and C). The modified PAM and sgRNA served two functions. First, the nucleotide nonsense alteration allowed the transformation to avoid the cleavage of the Cas9/sgRNA complex again to recover untransformed cells; and, second, the elimination of the BlpI restriction site provided a means to confirm that the site-directed mutation had been successful because the transformed cells would have a different restriction profile compared with the wild type. The pHN216-rpsL128 plasmid was successfully introduced to C. michiganensis cells by electroporation and the resulting Neoresistant transformants were selected for further analysis. Amplification of the rpsL flanking region from both the wild type and selected transformants using the rpsLF-F/rpsLF-R primer set (Supplementary Table S1) coupled with BlpI digestion confirmed the success of the mutagenesis, because the transformant produced a single band of 2,486 bp, whereas the wild type yielded a smaller band corresponding to two restriction fragments 1,281 and 1,205 bp in length (Fig. 2D). Subsequent DNA sequencing of the transformants revealed that they did, indeed, contain the A to $\mathrm{G}$ point mutation associated with Str resistance (Fig. 2E), which was confirmed by phenotype analysis because the $\Delta r p s L^{A 128 G}$ mutant was found to have a minimal inhibitory concentration (MIC) value in excess of $3,000 \mu \mathrm{g} / \mathrm{ml}$, which far exceeded the 
$8 \mu \mathrm{g} / \mathrm{ml}$ obtained with the wild-type isolate BT0505 (data not shown). Taken together, these results not only confirmed the findings of previous research regarding the link between the sitespecific mutation (A to $G$ ) at the 128th nucleotide acid of the rpsL gene and Str resistance but also demonstrated that CRISPR/ Cas9-mediated transformation could be an extremely useful technique for genetic manipulation in Clavibacter spp.

\section{CRISPR/Cas9-mediated deletion}

of celA and katA in C. michiganensis.

Having established that CRISPR/Cas9 could be utilized for sitedirected mutagenesis in $C$. michiganensis, the current study went on to investigate its potential to generate gene knockout mutants. In this case, the pHN216-rpsL128 described above was utilized as a template plasmid for the development of two new plasmids, pHN216-celA and pHN216-katA, that were designed to knockout the CelA cellulase (located on pCM1) and KatA catalase (CAT) (located on the chromosome), respectively, of $C$. michiganensis (Fig. 3A). This was achieved by simply replacing the $r p s L$ sequences and sgRNA with flanking regions from celA or katA and the sgRNA with gene-specific sequences designed using the Eukaryotic Pathogen CRISPR guide RNA/DNA Design Tool via HindIII/AfIII digestion.

Initial analysis of the transformants obtained from electroporation with pHN216-celA using PCR and the celAF-F/celAF-R primer set (Supplementary Table S1) identified two transformants, 6 and 10 from 14 transformants, that produced a 1,220-bp product in addition to the 3,461-bp product found in the wild type (Fig. 3B), which indicated that incomplete deletion had occurred as a result of the low efficiency of Cas9 cleavage coupled with the bacteria carrying multiple copies of the pCM1 plasmid that encoded the celA gene. However, when these
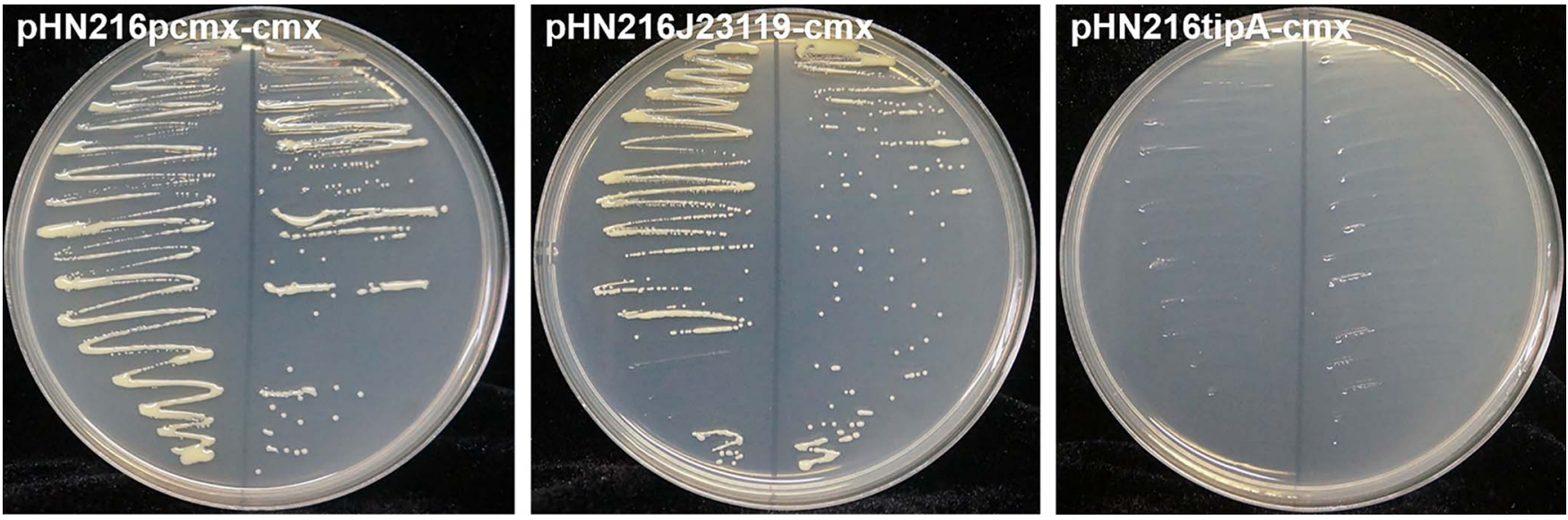

Fig. 1. Availability of candidate promoters in driving the expression of the chloramphenicol resistance gene ( $\mathrm{cmx}$ ) in Clavibacter michiganensis. Transformation of $C$. michiganensis with three plasmids (pHN216pcmx-cmx, pHN216J23119-cmx, and pHN216tipA-cmx) containing the cmx chloramphenicol resistance gene demonstrated that only the native pcmx promoter and the J23119 constitutive promoter could efficiently drive expression in C. michiganensis, whereas the Streptomyces tipA promoter was nonfunctional and prevented the growth of transformants on Luria-Bertani containing chloramphenicol at $10 \mu \mathrm{g} / \mathrm{ml}$.

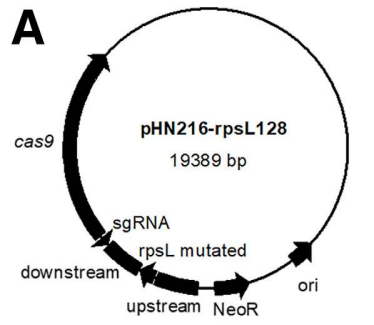

D

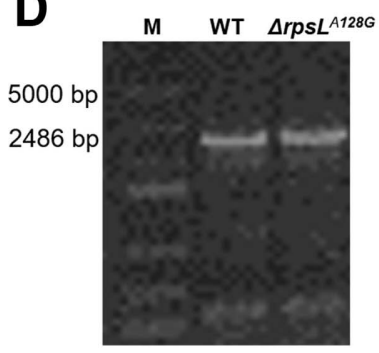

B

$$
\begin{array}{ll|l|l}
\text { WT } & \text { CA A A A A G } \\
r p s L^{128} & \text { CA A G A A G }
\end{array}
$$$$
\text { A128G }
$$

C

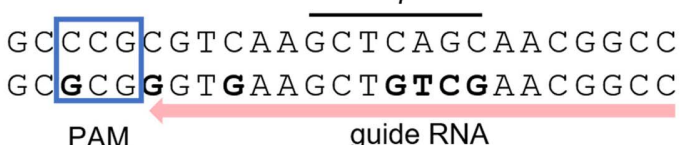

GC C C G G T CA A G C T CA G CA A C G C C
GCGCGG T GAAG T T T T GAA C G G C

PAM
$\mathbf{E}$

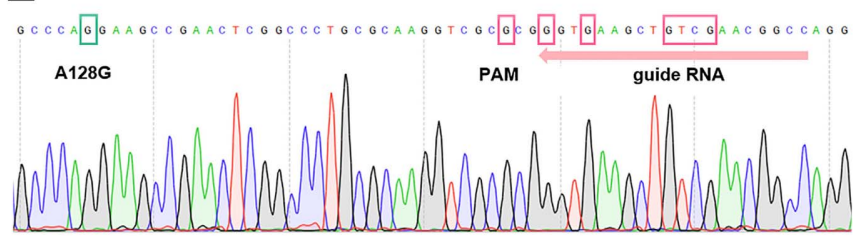

Fig. 2. CRISPR/Cas9-mediated site-directed mutagenesis of the Clavibacter michiganensis rpsL gene. A, pHN216-rpsL128 plasmid, which contained cas 9 under the control of the pcmx promoter. B, The 500-bp upstream and downstream regions of the $C$. michiganensis rpsL gene that included the A to $\mathrm{G}$ point mutation at the 128th nucleotide. C, A nonsense altered single-guide RNA (sgRNA) sequence that lacked a functional protospacer adjacent motif (PAM) sequence and had an altered sequence to eliminate the BlpI restriction site in the rpsL gene, all under the control of the J23119 promoter, were used to transform $C$. michiganensis by electroporation. D, PCR coupled with restriction digestion analysis confirmed that the transformants $\left(\Delta r p s L^{A 128 G}\right)$ lacked the BlpI restriction site and, therefore, yielded a single larger fragment $(2,486 \mathrm{bp})$ compared with the wild type (WT), which produced two fragments $(1,281$ and 1,205 bp) of roughly the same size. Lane $\mathrm{M}=$ DNA marker. E, DNA sequencing confirmed that the rpsL gene contained the desired changes in sequence that resulted in the $\Delta r p s L^{A 128 G}$ mutant exhibiting a streptomycin-resistant phenotype (data not shown). 
transformants were subcultured for more than one round and streaked to single colonies, several individuals (10-1, 10-4, and 10-7) were identified that yielded only the 1,220-bp fragment, which were further confirmed by DNA sequencing (Fig. 3C and D). Furthermore, none of the subcultured transformants produced the characteristic 481-bp fragment using the celAI-F/celAI-R primer set, which was designed to amplify an internal region of the celA gene (Fig. 3C). In addition, phenotype analysis using Congo Red (Fig. 3E) revealed that none of the three transformants produced the orange halo indicative of cellulase activity, as seen in the $C$. michiganensis reference strain NCPPB382, the wild-type parental isolated BT0505, and the parental isolate transformed with pHN216 as a negative control for the transformation. Taken together, the PCR and phenotype evidence indicated that the subcultured transformants were, indeed, $\Delta c e l A$ mutants, and that CRISPR/Cas9-mediated transformation was an effective method for producing gene knockout mutants in $C$. michiganensis.

The success of the CRISPR/Cas9 method was further confirmed in transformants obtained from electroporation with pHN216-katA. In this case, all of the subcultured transformants were found to produced smaller PCR products from the katAF-F/ katAF-R primer set designed to the katA flanking region, which
A

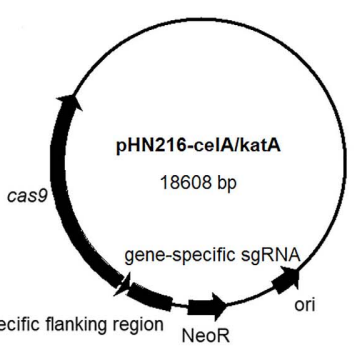

B

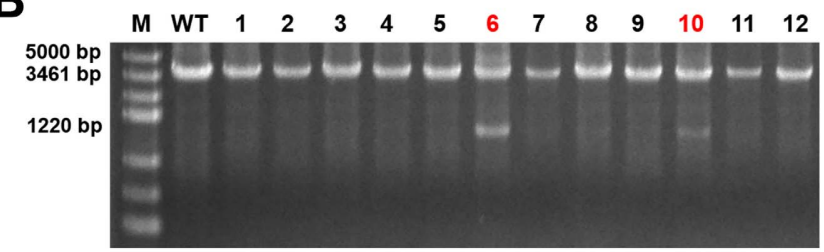

C

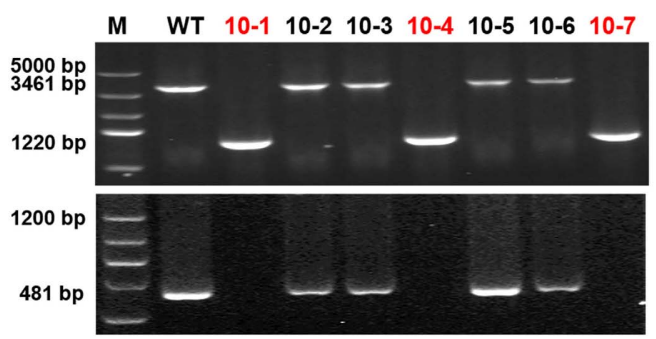

$\mathbf{F}$

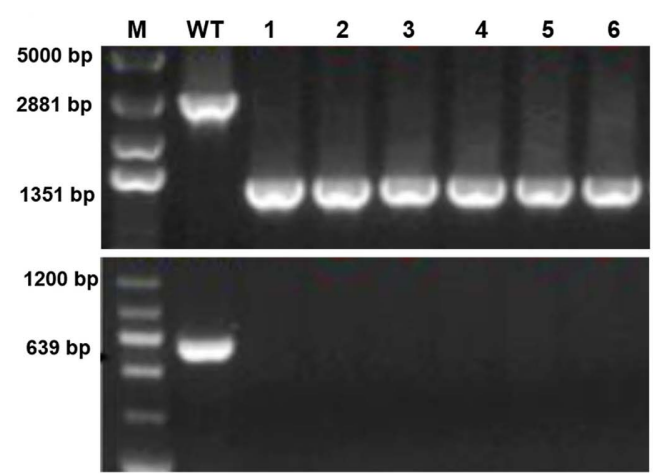

H
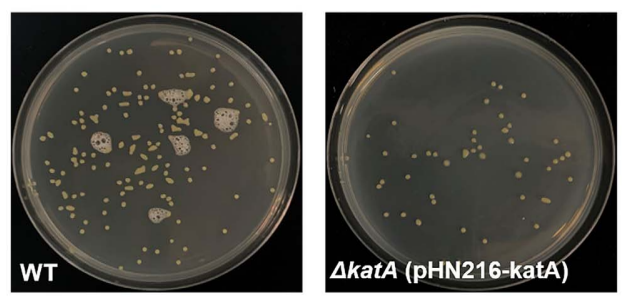

D

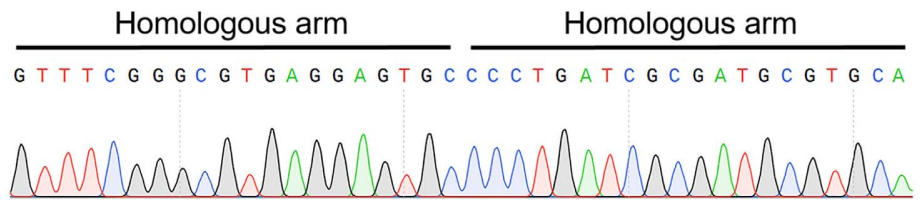

$\mathbf{E}$

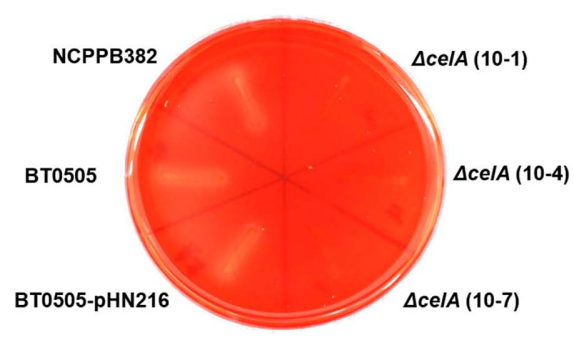

G

Homologous arm

Homologous arm

CAGCGGATCACCGCCGCGGCGGTGTTTCTCCTGTCAGCG G

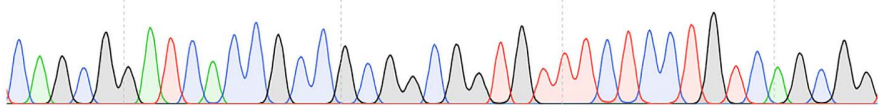

Fig. 3. CRISPR/Cas9-mediated deletion of the celA and katA genes of Clavibacter michiganensis. A, The pHN216-rpsL128 vector was used as a template plasmid for gene deletion, in which the rpsL donor DNA and single-guide RNA (sgRNA) were substituted for gene-specific flanking regions and sgRNA corresponding to either celA or katA, resulting in plasmids pHN216-celA and pHN216-katA. B, PCR analysis of the transformants resulting from electroporation with pHN216-celA indicted that only two (6 and 10) had altered profiles in comparison with the wild type (WT). Lane M = DNA marker. C, After streaking to purity, PCR targeting the celA flanking region and an internal celA sequence identified several deletion mutants (10-1, 10-4, and 10-7) that $\mathbf{D}$, were later confirmed by DNA sequencing. E, Lack of cellulase activity in the Congo Red assay failed to produce the orange halos observed in the WT (BT0505), type C. michiganensis isolate (NCPPB382), and transformant carrying an empty vector (BT0505-pHN216). F, Similar PCR analysis of the pHN216-katA transformants, all of which produced smaller fragments during amplification of the katA flanking region and none corresponding to the internal katA sequence, indicated a higher efficiency of gene deletion. G, DNA sequencing indicated the deletion of gene katA. H, Phenotype analysis confirmed that all of the transformant colonies $(\Delta k a t A)$ lacked catalase activity, failing to produce the bubbles of oxygen observed in the WT upon the application of $\mathrm{H}_{2} \mathrm{O}_{2}$. 
were $1,351 \mathrm{bp}$ in length compared with $2,881 \mathrm{bp}$ for the wild type, and completely failed to produce a product from the katAI-F/katAI-R primer set designed to target an internal region of the katA gene (Fig. 3F). DNA sequencing confirmed successful deletion of the katA gene (Fig. 3G). Phenotype analysis revealed that none of the transformants produced the characteristic bubbles of oxygen when $\mathrm{H}_{2} \mathrm{O}_{2}$ was applied to colonies growing on LB agar, as seen in the wild-type parental isolate (Fig. $3 \mathrm{H}$ ), and the CAT activity was undetectable in mutants (Supplementary Fig. S1). These results further validated the potential of CRISPR/Cas9-mediated transformation as a method of gene knockout in $C$. michiganensis, not only the deletion of genes located on the plasmid but also genome-encoded genes.

\section{Verification of aminoglycoside antibiotics and 5-FC}

for use as selectable markers in $C$. michiganensis.

The first step toward adapting the pSelAct plasmid, which has previously been used for unmarked gene editing in $R$. equi, for use in Clavibacter was to verify the functionality of the selectable markers in $C$. michiganensis. Plate assays conducted using LB agar amended with the following aminoglycoside antibiotics, including Gen at $50 \mu \mathrm{g} / \mathrm{ml}$, kanamycin $(\mathrm{Km})$ at $50 \mu \mathrm{g} / \mathrm{ml}$, Neo at $50 \mu \mathrm{g} / \mathrm{ml}$, Str at $50 \mu \mathrm{g} / \mathrm{ml}$, or apramycin (Apr) at $100 \mu \mathrm{g} / \mathrm{ml}$, showed that $E$. coli cells with pSelAct-katA plasmid, in which the $c c d B$ suicide gene and the chloramphenicol resistance gene had been replaced by the flanking region of the katA gene, could generate colonies (except for Str). The counts of E. coli colonies on LB containing $\mathrm{Km}$ or Neo were lower than without antibiotic (Fig. 4A). Moreover, competent cells of $C$. michiganensis were not capable of regenerating on media containing Neo, Km, or Gen (Fig. 4B), which indicated that wild-type C. michiganensis was sensitive to these aminoglycoside antibiotics. The combined results confirmed that the $a a c(3) I V$ gene in the pSelAct vector responsible for conferring resistance to aminoglycoside antibiotics (except for Str) was functional and, consequently, Gen at $50 \mu \mathrm{g} / \mathrm{ml}$ was chosen for positive selection of transformants in the subsequent experiments.

Another experiment confirmed that 5-FC could be used for negative selection in $C$. michiganensis, because the wild-type C. michiganensis isolate was found to exhibit no growth inhibition on M9 agar containing 5-FC, whereas transformants carrying the pSelAct-katA vector $\left(5-\mathrm{FC}^{\mathrm{S}} / \mathrm{Gen}^{\mathrm{R}}\right)$, which contained the $\operatorname{codA}:$ upp cassette, were completely inhibited by $5-\mathrm{FC}$ at $100 \mu \mathrm{g} / \mathrm{ml}$, which indicated that $\operatorname{codA}::$ upp could endow 5-FC sensitivity to $C$. michiganensis (Fig. 5A and B). However, it was interesting to note that, when the experiment was repeated substituting LB for M9 agar, all of the bacterial samples, including the $C$. michiganensis transformants carrying the pSelActkatA vector, were capable of growth on LB agar containing 5-FC, which indicated that the use of M9 agar was critical for effective 5-FC selection (Fig. 5C and D).

\section{Unmarked gene deletion via homologous recombination and CRISPR/Cas9-mediated transformation.}

Although the $\Delta$ katA mutant generated using the pHN216katA was adequate for further phenotype analysis, the fact that it contained the transformation vector expressing Neo resistance limited its potential in the development of further mutants with multiple gene deletions. However, the transformants carrying pSelAct-katA (Fig. 6A) were also confirmed by PCR analysis because they produced a band of $1,351 \mathrm{bp}$, except for the $2,881 \mathrm{bp}$ seen in the wild type (Fig. 6B). The 5-FC counterselection on M9 agar supplemented with 5-FC, which was endowed by the codA::upp cassette of the pSelAct-katA vector, provided a solution to this problem. This was simply achieved by subculture and shaking the candidate transformants in LB broth; then, $100 \mu \mathrm{l}$ of suspension was inoculated onto another LB broth for second shaking. This process was repeated one more time, and the $10^{-5}$ and $10^{-4}$ dilutions of each round of shaking cultures were plated onto M9 agar with 5-FC at $100 \mu \mathrm{g} / \mathrm{ml}$. Then, these 5-FC-resistant colonies were picked onto LB agar with or without Gen. Transformants exhibiting the $5-\mathrm{FC}^{\mathrm{R}} / \mathrm{Gen}^{\mathrm{S}}$ feature were verified by PCR and DNA sequencing (Fig. 6C and D). It was found that the more rounds of subculture in the absence of Gen the more efficient the process, because the numbers of transformants recovered were found to increase from 0 in the first $24 \mathrm{~h}$ to $4.65 \%$ in the second and $11.54 \%$ in the third (data not shown). The recovery of this $5-\mathrm{FC}^{\mathrm{R}} / \mathrm{Gen}^{\mathrm{S}} \Delta k a t A$ mutant (Figs. 5 and 6) confirmed that the $\operatorname{codA}::$ upp cassette and 5-FC selection could be an effective method to achieve unmarked gene deletion in $C$. michiganensis via homologous recombination.

The study then went on to investigate whether a similar system could be applied to CRISPR/Cas9-mediated transformation by integrating the $\operatorname{codA}::$ upp cassette into the pHN216-katA plasmid. As expected, the derivative vector pHN216-katAcodAupp (Fig. 6E) successfully produced transformants which, when verified by PCR and DNA sequencing, produced profiles that indicated that gene deletion had occurred (data not shown). After three cycles of subculture in liquid media lacking Neo,
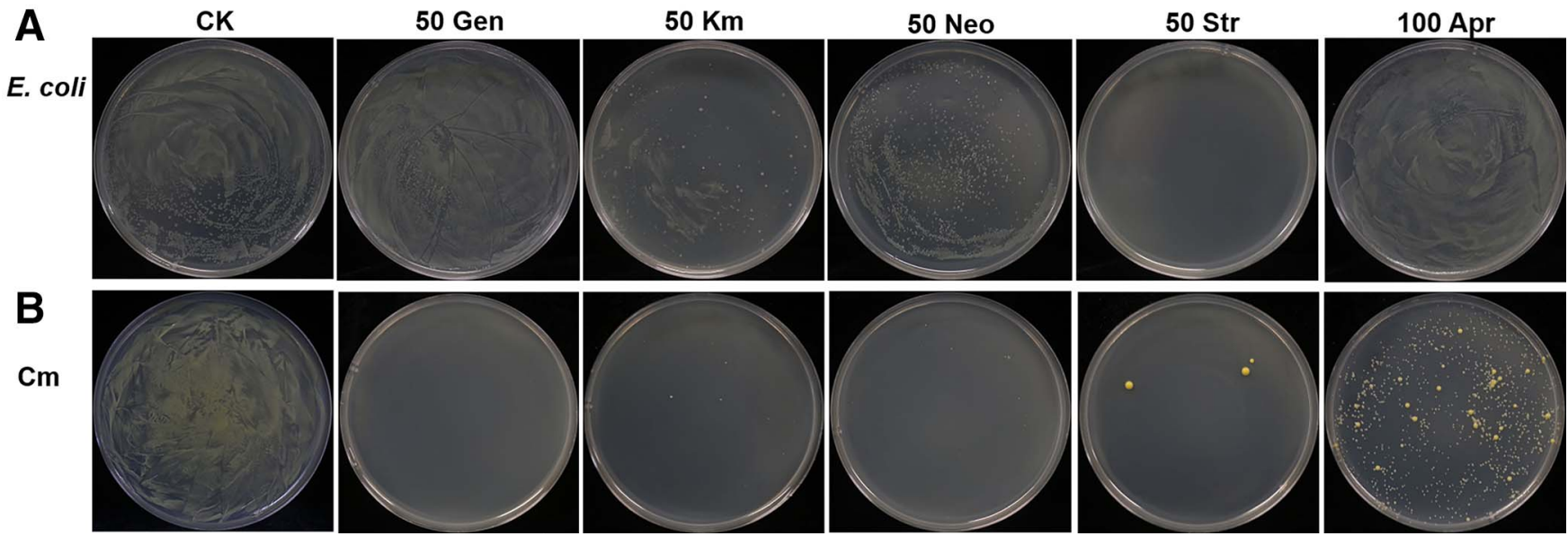

Fig. 4. Sensitivity of Escherichia coli and Clavibacter michiganensis to aminoglycoside antibiotics. A, E. coli cells harboring pSelAct-katA plasmid and B, wild-type C. michiganensis competent cells $(\mathrm{Cm})$ were plated on Luria-Bertani (LB) agar supplement with gentamicin $(\mathrm{Gen})$ at $50 \mu \mathrm{g} / \mathrm{ml}, \mathrm{kanamycin}$ $(\mathrm{Km})$ at $50 \mu \mathrm{g} / \mathrm{ml}$, neomycin (Neo) at $50 \mu \mathrm{g} / \mathrm{ml}$, streptomycin (Str) at $50 \mu \mathrm{g} / \mathrm{ml}$, and apramycin (Apr) at $100 \mu \mathrm{g} / \mathrm{ml}$. LB agar without any antibiotic was used as control (CK). 
followed by plating on M9 agar supplemented with 5-FC for counterselection, 5-FC ${ }^{\mathrm{R}} \Delta$ katA mutants were recovered that had evidently lost the pHN216-katA-codAupp vector because they were no longer able to grow on LB amended with Neo (Fig. $6 \mathrm{~F})$. Phenotype analysis confirmed that both the $5-\mathrm{FC}^{\mathrm{R}} / \mathrm{Gen}^{\mathrm{S}}$ $\triangle$ katA mutants obtained by homologous recombination using pSelAct-katA, and the $5-\mathrm{FC}^{\mathrm{R}} / \mathrm{Neo}^{\mathrm{S}} \Delta$ katA mutants generated via CRISPR/Cas9-mediated transformation using pHN216-katAcodAupp, completely lacked the CAT activity observed in the wild-type BT0505 (Fig. 6G; Supplementary Fig. S1). Taken together, these results confirmed that CRISPR/Cas9-mediated transformation with 5-FC counterselection was an efficient method for creating unmarked gene knockout mutants that could be further transformed to produce $C$. michiganensis mutants with multiple gene knockouts.

\section{DISCUSSION}

The current study developed a CRISPR/Cas9-mediated genome editing strategy that was successfully used for sitedirected mutagenesis of the $r p s L$ gene to generate Str-resistant transformants, as well as to produce knockout mutants of the C. michiganensis celA and katA genes that lacked cellulase and CAT activity, respectively. In addition, the study also integrated an efficient method of counterselection that exploited the cytotoxic effect of 5-FC associated with the $\operatorname{codA}:: u p p$ cassette to facilitate the production of an unmarked $\Delta k a t A$ mutant without the need for large-scale colony validation. The combination of the two approaches resulted in an improved CRISPR/Cas9 system that could be implemented numerous times within a single C. michiganensis cell line to establish mutants with alterations to multiple genes.

Traditionally, the use of CRISPR/Cas-mediated transformation in bacteria has relied on a two-plasmid approach (especially CRISPR/Cas9), in which the cas 9 gene and sgRNA are located separately on two compatible plasmids: a pCas9 plasmid carrying the transactivating crRNA and cas9 gene, and a second gRNA plasmid carrying the array of CRISPR spacers (Jiang et al. 2013; Liu et al. 2017). However, the current study adapted a single-plasmid system recently developed for the transformation of Streptomyces (Huang et al. 2015), in which the cas 9 gene and an sgRNA, as well as a flanking region of the target gene, which acts as a donor for homology directed repair, were carried on one plasmid. The analogous plasmid used in the current study placed the cas 9 gene under the control of the pcmx promoter, while retaining the $\mathrm{J} 23119$ promoter to drive the expression of the sgRNA. Although the J23119 promoter has previously been used for the expression of sgRNA in E. coli and S. coelicolor (Huang et al. 2015; Larson et al. 2013), to the best of our knowledge this represents the first report of the J23119 promoter being used to drive expression in $C$. michiganensis. Indeed, research regarding appropriate promoters for the genetic
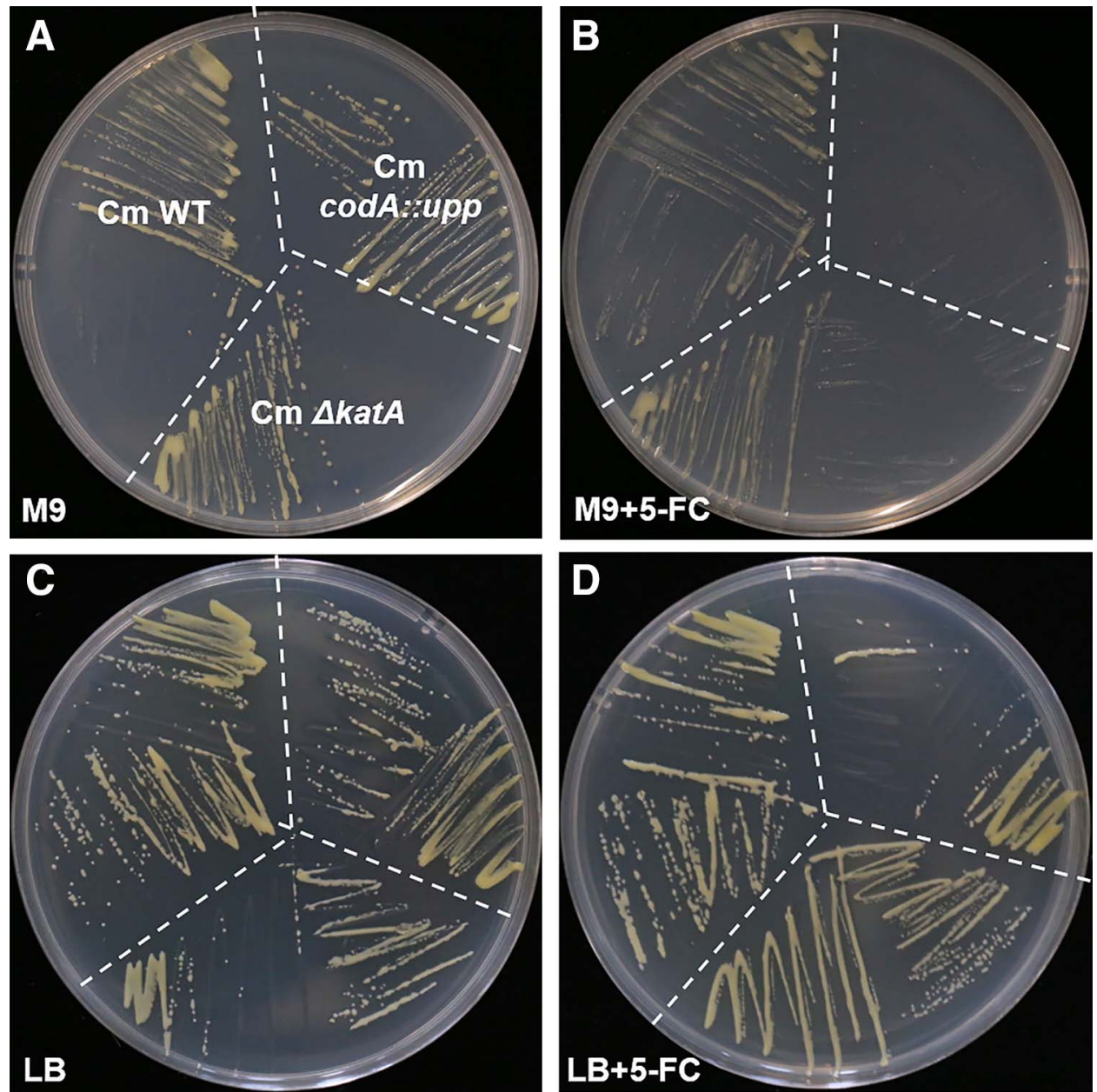

Fig. 5. Confirmation of 5-fluorocytosine (5-FC) counterselection in Clavibacter michiganensis. Panels show the growth of the wild-type (WT), recombinant strain transformed with pSelAct-katA vector, which contained the codA::upp cassette (C. michiganensis codA::upp), and transformants lacking the plasmid as a result of counterselection $\left(5-\mathrm{FC}^{\mathrm{R}} / \mathrm{Gen}^{\mathrm{s}}, C\right.$. michiganensis $\Delta$ katA $)$, as well as the growth of the WT $C$. michiganensis on four different media: A, M9 agar; B, M9 agar containing 5-FC at $100 \mu \mathrm{g} / \mathrm{ml}$; C, Luria-Bertani (LB) agar; and D, LB agar containing 5-FC at $100 \mu \mathrm{g} / \mathrm{ml}$. 
modification of $C$. michiganensis is currently very limited, and the identification of more efficient $C$. michiganensis-specific promoters could be one avenue to increase the editing efficiency of the CRISPR/Cas9 system and decrease the rounds of subculture required to eliminate incomplete deletion mutants, especially when there may be multiple copies of a target gene carried on a plasmid rather than within the main bacterial genome. Another strategy might be to develop a novel plasmid based on the CRISPR/Cas12a (Cpf1) system. Previous research has shown that Cas12a recognizes a different PAM sequence and exhibits more precise cleavage of target sequences compared with Cas9 (Leenay et al. 2016). Gene editing strategies based on CRISPR/ Cas12a have already been developed in E. coli, Corynebacterium glutamicum, Yersinia pestis, and Mycobacterium smegmatis (Jiang et al. 2017; Yan et al. 2017), and have been found to provide a highly efficient method of genetic manipulation in these bacteria.

A major limitation of conventional homologous recombination based approaches for producing gene knockout mutants is that they leave genetic "scars" because the antibiotic resistance
A

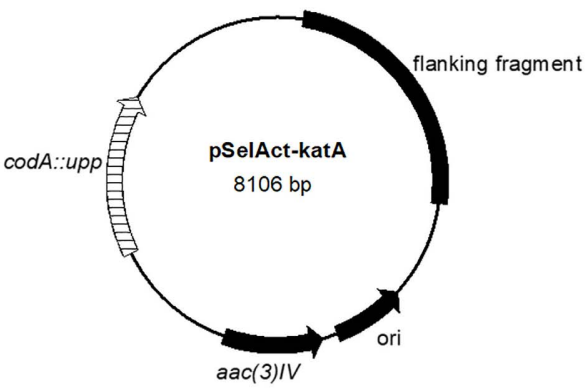

C

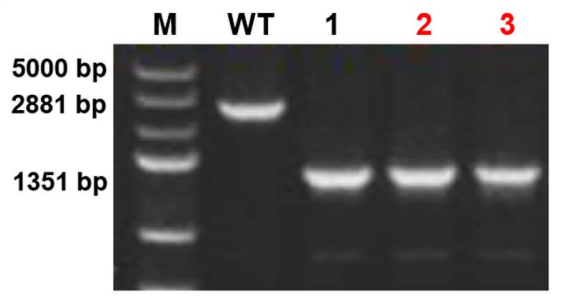

$1200 \mathrm{bp}$

$639 \mathrm{bp}$

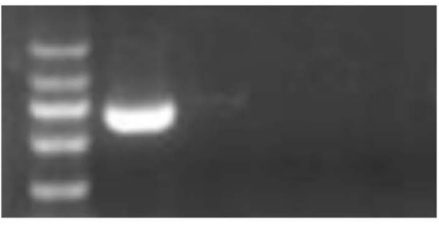

$\mathbf{F}$
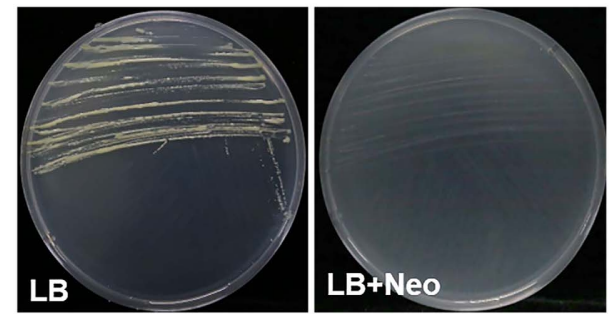

G

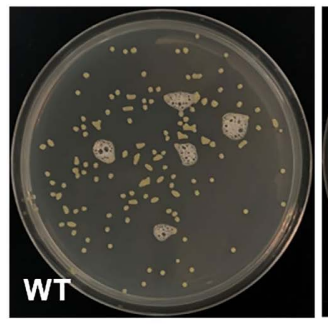

B

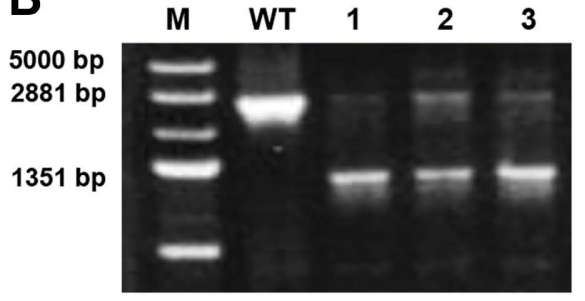

D

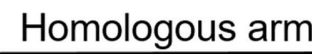

Homologous arm

CAGCGGATCACCGCCGCGGCGGTGTTTCTCCTGTCAGCGG

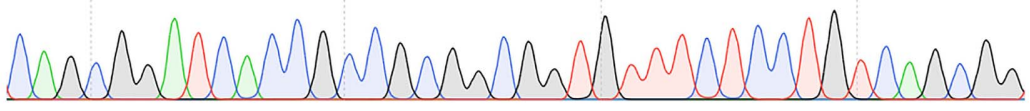

$\mathbf{E}$
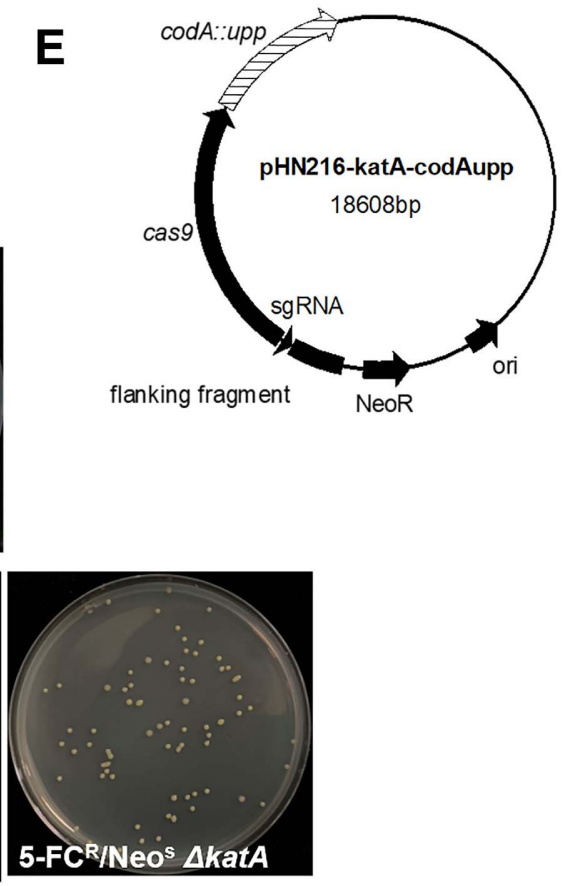

Fig. 6. Unmarked deletion of the Clavibacter michiganensis katA gene via homologous recombination and CRISPR/Cas9-mediated transformation. A, Electroporation with the pSelAct-katA plasmid, which contained the aminoglycoside antibiotics resistance cassette $(\operatorname{aac}(3) I V)$, and the 5-fluorocytosine (5-FC) sensitivity cassette ( $\operatorname{codA}::$ upp), as well as 500-bp upstream and downstream flanking regions of the katA gene, resulted in B, the regeneration of several C. michiganensis transformants (1,2, and 3) that had altered PCR profiles compared with the wild-type (WT). Lane M = DNA marker. C, After further subculture, two transformants were recovered that produced smaller PCR products when the flanking region was amplified and none corresponding to an internal katA sequence. D, DNA sequencing also indicated that complete deletion had occurred. E, Similar PCR results were obtained after transformation with the pHN216-katA-codAupp plasmid, which contained the codA::upp cassette in addition to cas 9 and the katA-specific single-guide RNA (sgRNA) and flanking region (data not shown). F, Subculture of the pHN216-katA-codAupp transformants in broth lacking antibiotic selection followed by counterselection on M9 media containing 5-FC resulted in transformants no longer capable of growth in the presence of antibiotic selection, indicating the loss of the transformation vector. G, Phenotype analysis confirmed that both the pSelAct-katA- and pHN216-katA-codAupp-derived transformants $\left(5-\mathrm{FC}^{\mathrm{R}} / \mathrm{Gen}^{\mathrm{S}} \Delta k a t A\right.$ and $5-\mathrm{FC}^{\mathrm{R}} / \mathrm{Neo}^{\mathrm{S}} \Delta k a t A$, respectively) lacked catalase activity, failing to produce the bubbles of oxygen observed in the WT upon the application of $\mathrm{H}_{2} \mathrm{O}_{2}$. 
markers (Gen or chloramphenicol) remain in the genome, limiting the potential for further genetic manipulation (Hwang et al. 2019; Jahr et al. 2000). Thus, the confirmation that the 5-FC counterselection developed for unmarked gene deletion in $R$. equi (van der Geize et al. 2008) can also be applied in Clavibacter michiganensis represents a significant advancement for the study of this important plant-pathogenic species. The use of oligotrophic M9 medium rather than nutrient-rich LB medium seemed to be a critical factor in the effectiveness of the counterselection system, which was probably a consequence of the pyrimidine salvage pathway that can affect 5-FC uptake under nutrient-rich conditions (van der Geize et al. 2008). It is also important to note that although natural 5-FC resistance has been documented in many species of actinobacteria (van der Geize et al. 2008), further research is required to determine whether the 5-FC resistance observed in $C$. michiganensis occurs in other Clavibacter spp., and whether this counterselection can be universally applied across the genera.

Although the CRISPR/Cas9 coupled with 5-FC counterselection system developed in the current study could be improved further-for example by the use of multiple sgRNA sequences (Ren et al. 2021; Z. Zhang et al. 2016) - it still represents a major breakthrough for genome editing in $C$. michiganensis, by providing a convenient and reliable method for both sitedirected mutagenesis and the production of unmarked deletion mutants. The application of such technology could lead to rapid advances in our understanding of the host-pathogen interaction of $C$. michiganensis, as well as providing the groundwork for the genetic manipulation of other Clavibacter spp.

\section{MATERIALS AND METHODS}

\section{Strains, plasmids, and culture conditions.}

The parental wild-type C. michiganensis isolate BT0505 (24944; China Center of Industrial Culture Collection) used in the current study was originally isolated from infected tomato plants growing in the Inner Mongolia province of China in 2005 (Jiang et al. 2016). All $C$. michiganensis strains were routinely maintained on LB agar (tryptone at $10 \mathrm{~g} /$ liter, yeast extract at $5 \mathrm{~g} / \mathrm{liter}$, and $\mathrm{NaCl}$ at $5 \mathrm{~g} /$ liter) at $28^{\circ} \mathrm{C}$ for 3 days, while a modified $\mathrm{M} 9$ medium $\left(\mathrm{Na}_{2} \mathrm{HPO}_{4} \cdot 12 \mathrm{H}_{2} \mathrm{O}\right.$ at $6 \mathrm{~g} /$ liter, $\mathrm{KH}_{2} \mathrm{PO}_{4}$ at $3 \mathrm{~g} / \mathrm{liter}$, $\mathrm{NH}_{4} \mathrm{Cl}$ at $1 \mathrm{~g} /$ liter, $\mathrm{NaCl}$ at $0.5 \mathrm{~g} / \mathrm{liter}, 1 \mathrm{mM} \mathrm{MgSO}{ }_{4} \cdot 7 \mathrm{H}_{2} \mathrm{O}, 0.01$ $\mathrm{mM} \mathrm{CaCl} 2 \cdot 2 \mathrm{H}_{2} \mathrm{O}$, glucose at $2 \mathrm{~g} /$ liter, methionine at $200 \mathrm{mg} / \mathrm{liter}$, thiamine at $200 \mathrm{mg} / \mathrm{liter}$, nicotinic acid at $20 \mathrm{mg} / \mathrm{liter}$, and agar at $16 \mathrm{~g} /$ liter) (Chalupowicz et al. 2010) and an extended period of incubation ( 7 days) was used during the 5-FC counterselection procedure. Similarly, LB broth was used to multiply cells prior to transformation, while sorbitol broth (SB) (tryptone at $10 \mathrm{~g} / \mathrm{liter}$, yeast extract at $5 \mathrm{~g} / \mathrm{liter}, \mathrm{NaCl}$ at $4 \mathrm{~g} / \mathrm{liter}$, D-sorbitol at $91 \mathrm{~g} / \mathrm{liter}, 20 \mathrm{mM} \mathrm{MgCl}_{2} \cdot 6 \mathrm{H}_{2} \mathrm{O}, 20 \mathrm{mM}$ $\mathrm{CaCl}_{2} \cdot 2 \mathrm{H}_{2} \mathrm{O}$, and agar at $16 \mathrm{~g} /$ liter if required) was used to recover C. michiganensis transformants after electroporation. When selection was required, antibiotics, including $\mathrm{Neo}, \mathrm{Gm}$, and chloramphenicol, were added to a finial concentration of 50, 50, and $10 \mu \mathrm{g} / \mathrm{ml}$, respectively, while, during the negative selection, 5-FC was added at $100 \mu \mathrm{g} / \mathrm{ml}$. The 5-FC (Sigma) stock solution itself was prepared by dissolution in water $(10 \mathrm{mg} / \mathrm{ml})$, a process that was accelerated by heating in a $50^{\circ} \mathrm{C}$ water bath. The optical density of bacterial suspensions was measured at $580 \mathrm{~nm}\left(\mathrm{OD}_{580}\right)$ using an ultraviolet spectrophotometer U-T6A (Yipu, Shanghai, China).

The initial plasmid construction was performed using E. coli DH5 $\alpha$ competent cells using conventional cloning procedures, with the plasmids used in the $C$. michiganensis transformation being prepared using the TIANprep Mini Plasmid Kit (TIANGEN Biotech, Beijing, China). All plasmids used in the study have been listed in Table 1 .

\section{Electroporation of $C$. michiganensis cells.}

The electroporation protocol used to routinely transform C. michiganensis cells was adapted from a method detailed in a previous study (Kirchner et al. 2001). Briefly, cells of $C$. michiganensis $(250 \mathrm{ml})$ at the early $\log$ phase of growth $\left(\mathrm{OD}_{580}=0.6\right)$ were mixed with $20 \%$ (wt/vol) glycine stock solution to a final concentration of $2.5 \%(\mathrm{wt} / \mathrm{vol})$, and incubated at $28^{\circ} \mathrm{C}$ with shaking $(120 \mathrm{rpm})$ for $1 \mathrm{~h}$. The cells were then harvested by centrifugation and washed in $25 \mathrm{ml}$ of ice-cold distilled water three times, before being washed in ice-cold 10\% (vol/vol) glycerol twice. The competent cells were then resuspended in $500 \mu \mathrm{l}$ of $15 \%$ glycerol and divided into five tubes, which were stored at $-80^{\circ} \mathrm{C}$ until required. The electroporation itself was performed at $12.5 \mathrm{kV} / \mathrm{cm}$ with a time constant of 12 to $16 \mathrm{~ms}$. The transformed cells were then mixed with $400 \mu \mathrm{l}$ of SB liquid medium and incubated at $28^{\circ} \mathrm{C}$ with shaking $(200 \mathrm{rpm})$ for $3 \mathrm{~h}$ before being spread on SB agar plates containing the appropriate antibiotic for selection. Individual colonies were picked after incubation at $28^{\circ} \mathrm{C}$ for 4 to 5 days, and streaked to purity on LB amended with the selective antibiotic.

Table 1. Plasmids used in the current study

\begin{tabular}{|c|c|c|}
\hline Plasmid & Relevant characteristics $^{\mathbf{a}}$ & Source \\
\hline pHN216 & Escherichia coli-Clavibacter shuttle vector; $\mathrm{Neo}^{\mathrm{R}}$ & Laine et al. 1996 \\
\hline pOKU9cmB $\alpha$ & Donor of the $c m x$ gene and pcmx promoter & Kaup et al. 2005 \\
\hline pKCcas9dO & Donor of the tipA and $\mathrm{J} 23119$ promoters as well as the $\operatorname{cas} 9$ gene & Huang et al. 2015 \\
\hline pHN216tipA-cmx & Derivative of $\mathrm{pHN} 216 ; \mathrm{Neo}^{\mathrm{R}}$ & Current study \\
\hline pHN216J23119-cmx & Derivative of $\mathrm{pHN} 216 ; \mathrm{Neo}^{\mathrm{R}}, \mathrm{Chl}^{\mathrm{R}}$ & Current study \\
\hline pHN216pcmx-cmx & Derivative of pHN216; $\mathrm{Neo}^{\mathrm{R}}, \mathrm{Chl}^{\mathrm{R}}$ & Current study \\
\hline pHN216-rpsL128 & $\begin{array}{l}\text { Derivative of pHN216 for site-directed mutation of } r p s L \text { by CRISPR/Cas9- } \\
\text { mediated transformation; } \mathrm{Neo}^{\mathrm{R}}\end{array}$ & Current study \\
\hline pHN216-celA & $\begin{array}{l}\text { Derivative of pHN216-rpsL128 for knockout of celA by CRISPR/Cas9- } \\
\text { mediated transformation; Neo }\end{array}$ & Current study \\
\hline pHN216-katA & $\begin{array}{l}\text { Derivative of pHN216-rpsL128 for knockout of katA by CRISPR/Cas9- } \\
\text { mediated transformation; } \mathrm{Neo}^{\mathrm{R}}\end{array}$ & Current study \\
\hline pSelAct & $\begin{array}{l}\text { Suicide plasmid, including the } a a c(3) I V, c c d B \text {, and } \operatorname{cod} A: \because u p p \text { cassettes; } \mathrm{Gen}^{\mathrm{R}} \text {, } \\
\quad \mathrm{Chl}^{\mathrm{R}}, 5-\mathrm{FC}^{\mathrm{S}}\end{array}$ & $\begin{array}{l}\text { Savory et al. 2020; van der } \\
\quad \text { Geize et al. } 2008\end{array}$ \\
\hline pSelAct-katA & $\begin{array}{l}\text { Derivative of pSelAct containing 500-bp flanking regions for unmarked } \\
\text { knockout of katA by homologous recombination; } \mathrm{Gen}^{\mathrm{R}}, 5-\mathrm{FC}^{\mathrm{S}}\end{array}$ & Current study \\
\hline pHN216-katA-codAupp & $\begin{array}{l}\text { Derivative of pHN216-katA including the codA::upp cassette for unmarked } \\
\text { knockout of katA by CRISPR/Cas9-mediated transformation. } \text { Neo }^{\mathrm{R}}, 5-\mathrm{FC}^{\mathrm{S}}\end{array}$ & Current study \\
\hline
\end{tabular}

${ }^{a}$ Abbreviations: Neo = neomycin, $\mathrm{Chl}=$ chloramphenicol, Gen $=$ gentamicin, and 5-FC $=5$-fluorocytosine; superscripts ${ }^{\mathrm{R}}$ and ${ }^{\mathrm{S}}$ indicate resistant and sensitive, respectively. 


\section{Screening for functional promoters}

\section{to facilitate CRISPR/Cas9-mediated transformation}

of $C$. michiganensis.

The development of the CRISPR/Cas9 system for use in C. michiganensis first required the identification of functional promoters that could drive expression in Clavibacter spp. Two candidates were initially considered: the promoter from the tipA gene and the constitutive promoter J23119, both of which had been used successfully in the pKCcas9dO plasmid to express $\operatorname{cas} 9$ and sgRNA, respectively, in S. coelicolor (Huang et al. 2015). The native promoter of $c m x$ cassette (referred as pcmx) from plasmid pOKU $9 \mathrm{cmB} \alpha$ was used as a positive control to turn on the expression of the chloramphenicol resistant gene in $C$. michiganensis (Kaup et al. 2005). The E. coli-Clavibacter shuttle vector pHN216 digested by HindIII/EcoRV was used as host backbone for all DNA fragments (the promoter and chloramphenicol-resistant gene), and resulted in recombined plasmids pHN216tipA-cmx, pHN216J23119-cmx, and pHN216pcmx-cmx. Each of the three plasmids were then introduced into competent $C$. michiganensis cells by electroporation, and verified on LB agar containing chloramphenicol at $10 \mu \mathrm{g} / \mathrm{ml}$.

\section{Construction of gene-editing plasmids for CRISPR/Cas9-mediated transformation of $C$. michiganensis.}

Having established that both the pcmx and J23119 promoters could successful drive expression in $C$. michiganensis, a series of gene-editing plasmids were constructed with cas 9 under the control of the pcmx promoter and the sgRNA under the control of the J23119 promoter to investigate whether the CRISPR/Cas9 system could be used for site-directed mutagenesis and the creation of deletion mutants. The first step in the process involved the creation of a pcmx-cas 9 fusion product, which was produced by amplifying the pcmx promoter from $\mathrm{pOKU} 9 \mathrm{cmB} \alpha$ using the pcmx-F/pcmx-R primer set (Supplementary Table S1), which introduced an AflII restriction site (CTTAAG) to facilitate cloning. The cas 9 gene was amplified from pKCcas9dO and ligated to the pcmx promoter by overlap PCR. The 500-bp upstream, $r p s L$ gene with $\mathrm{A} 128 \mathrm{G}$ point mutation and downstream regions were amplified from genomic template DNA of wild-type isolate BT0505 using the rpsLU-F/rpsLU-R and rpsLD-F/rpsLD-R primer sets (Supplementary Table S1). Meanwhile, the rpsL-specific sgRNA, which was designed to a region near the 128th nucleotide of the rpsL gene and contained altered sequences to eliminate the PAM recognition sequence and BlpI restriction site (Fig. 2C), was amplified from pKCcas9dO template DNA using the sgRNA-F/rpsLsg-R primer set (Supplementary Table S1) These functional elements were then ligated into the pHN216 backbone digested by HindIII/EcoRV.

The pHN216-rpsL128 plasmid described above was also used as a template plasmid for the production of the celA and katA knockout mutants by simply replacing the $r p s L$-specific sgRNA and flanking regions. The sgRNA of celA and katA was amplified from pKCcas9dO template DNA using the sgRNA-F/celAsg-R and sgRNA-F/katAsg-R primer sets, respectively (Supplementary Table S1). The celA flanking regions were amplified from BT0505 template DNA by celA-F1/celA-R1 and celA-F2/celA-R2 primers, and the katA flanking regions were amplified by katA-F1/katA-R1 and katA-F2/katA-R2 (Supplementary Table S1). The resulting sgRNA elements and flanking regions were cloned into the HindIII/AfIIIdigested pHN216-rpsL128 backbone to produce pHN216-celA and pHN216-katA, respectively (Fig. 3A).

The pSelAct-katA plasmid (Fig. 6A) used for the unmarked katA gene deletion experiment was prepared by replacing the $c c d B$ suicide cassette and chloramphenicol resistance gene in pSelAct with the katA flanking regions. And pHN216-katAcodAupp plasmids (Fig. 6E) used for the unmarked CRISPR/
Cas9-mediated gene deletion experiments were constructed by introducing the $\operatorname{codA}:$ :upp cassette from pSelAct to EcoRV/ SspI-digested pHN216-katA.

All of the primers used during the cloning procedure were designed according to the instructions of the In-Fusion cloning system, which produced 15- to 18-bp overlap regions.

\section{Assessing the sensitivity of $C$. michiganensis to aminoglycoside antibiotics.}

The first step in determining whether the pSelAct suicide vector could be adapted for use in $C$. michiganensis was to assess the viability of its selectable markers in Clavibacter spp. The sensitivity of both $E$. coli and $C$. michiganensis to a range of aminoglycoside antibiotics associated with the $a a c(3) I V$ resistance gene detailed in the comprehensive antibiotic resistance database, including $\mathrm{Km}$ at $50 \mu \mathrm{g} / \mathrm{ml}$, Gen at $50 \mu \mathrm{g} / \mathrm{ml}$, Neo at $50 \mu \mathrm{g} / \mathrm{ml}$, Str at $50 \mu \mathrm{g} / \mathrm{ml}$, and Apr at $100 \mu \mathrm{g} / \mathrm{ml}$, was tested by plating on antibiotic-amended LB agar (Dubois et al. 2008; Vliegenthart et al. 1991). Aliquots (100 $\mu \mathrm{l}$ each) of $10^{6} \mathrm{CFU} / \mathrm{ml}$ bacterial suspensions of either E. coli transformed with the pSelAct-katA plasmid, in which the chloramphenicol resistance gene and $c c d B$ suicide cassette had been replaced by $500 \mathrm{bp}$ upstream and downstream sequences of the katA gene, or electrocompetent $C$. michiganensis cells were spread across the plates and assessed after $12 \mathrm{~h}$ of incubation at $37^{\circ} \mathrm{C}$ in the case of $\mathrm{E}$. coli and 5 days incubation at $28^{\circ} \mathrm{C}$ in C. michiganensis.

\section{5-FC negative selection in $C$. michiganensis.}

The 5-FC negative selection procedure was carried out according to the protocol of a previous study, with a few modifications (van der Geize et al. 2008). Briefly, C. michiganensis transformants carrying the pSelAct-katA plasmid were first inoculated in $10 \mathrm{ml}$ of LB broth in the absence of antibiotics and incubated at $28^{\circ} \mathrm{C}$ with shaking $(120 \mathrm{rpm})$ for $24 \mathrm{~h}$, before serial dilutions were prepared and 100- $\mu \mathrm{l}$ aliquots of the resulting bacterial suspensions $\left(10^{-5}\right.$ and $\left.10^{-4}\right)$ were plated on M9 agar plates supplemented with 5-FC at $100 \mu \mathrm{g} / \mathrm{ml}$. Meanwhile, 100- $\mu$ l suspensions were added into another $10 \mathrm{ml}$ of LB broth, shaken for $24 \mathrm{~h}$ again, and diluted bacterial suspension was spread on M9 agar with 5-FC. This process was repeated four times. After 9 days of incubation at $28^{\circ} \mathrm{C}$, individual colonies on $\mathrm{M} 9$ agar were selected and inoculated onto LB plates with and without Gen. Colonies that were found to be resistant to 5-FC but susceptible to Gen were further verified by PCR and DNA sequencing. Having established that counterselection was effective with $C$. michiganensis transformants carrying the pSelAct-katA plasmid, a similar process was later used for the counterselection of $C$. michiganensis transformants carrying the pHN216-katA-codAupp vector, although in the this case Neo at $50 \mu \mathrm{g} / \mathrm{ml}$ was used, replacing Gen for the antibiotic selection step.

\section{Assessing the phenotype of $\boldsymbol{C}$. michiganensis mutants.}

Str resistance. The MIC values for Str in the wild-type parental isolate BT0505, and the $\Delta r p s L^{A 128 G}$ mutant were determined by measuring their growth in liquid media amended with Str at 0 , $1,2,4,8,16,32,64,120,240$, and $512 \mu \mathrm{g} / \mathrm{ml}$ for the wild type and $0,100,200,300,400,500,1,000,2,000,3,000,4,000$, and $5,000 \mu \mathrm{g} / \mathrm{ml}$ for the mutant. Each culture was inoculated to a final concentration of $10^{6} \mathrm{CFU} / \mathrm{ml}$ and incubated at $28^{\circ} \mathrm{C}$ with shaking $(120 \mathrm{rpm})$ for $24 \mathrm{~h}$, before $\mathrm{OD}_{580}$ was measured using a Tecan infinite F200microplate reader (Tecan, Grǒdig, Austria). Each strain was represented by three replicates, and the entire experiment was performed three times.

Cellulase activity. The cellulase activity of the $\Delta$ celA mutant was investigated using the Congo Red test on M9 plates containing $0.5 \%$ carboxyl methyl cellulose (CMC), as described in a previous study (Meletzus et al. 1993). The $\Delta$ celA mutant and 
wild-type isolate were streaked on M9-CMC plates and incubated at $28^{\circ} \mathrm{C}$ for 4 to 7 days before $10 \mathrm{ml}$ of $0.1 \%$ Congo Red was added to each plate. After a further 20 min of incubation, the dye was removed and the plates rinsed five or six times with $\mathrm{NaCl}$ at $1 \mathrm{~mol} /$ liter. The formation of orange halos around bacterial colonies indicated the presence of cellulase activity in the wild type, while the absence of halos in the $\Delta$ celA mutant indicated a loss of extracellular cellulase activity.

CAT activity. The absence or presence of CAT activity was determined using a very simple assay in which drops of $30 \%$ $\mathrm{H}_{2} \mathrm{O}_{2}(\omega)$ were applied to colonies of the wild-type $C$. michiganensis isolate and the $\Delta$ katA mutants that had been grown on $\mathrm{LB}$ agar for 3 days at $28^{\circ} \mathrm{C}$. The rapid formation of oxygen bubbles indicated the presence of CAT activity in the wild-type isolate, while the lack of bubbles in the mutants confirmed the loss of CAT activity.

\section{ACKNOWLEDGMENTS}

We thank J. Chang at Oregon State University and D. Stevens and G. Coaker at University of California-Davis for their generosity in providing the pSelAct plasmid and for their helpful advice, as well as Y. Lu at the Institute of Plant Physiology and Ecology of CAS Center for Excellence in Molecular Plant Sciences for kindly providing the pKCcas9dO plasmid.

\section{AUTHOR-RECOMMENDED INTERNET RESOURCES}

Codon Usage Database: http://www.kazusa.or.jp/codon/

CRISPR database: https://crispr.i2bc.paris-saclay.fr/

\section{LITERATURE CITED}

Ah-Fong, A. M. V., Boyd, A. M., Matson, M. E. H., and Judelson, H. S. 2021. A Cas12a-based gene editing system for Phytophthora infestans reveals monoallelic expression of an elicitor. Mol. Plant Pathol. 22: 737-752.

Andersen, L., Kilstrup, M., and Neuhard, J. 1989. Pyrimidine, purine and nitrogen control of cytosine deaminase synthesis in Escherichia coli $\mathrm{K}$ 12. Involvement of the $g \ln L G$ and purR genes in the regulation of codA expression. Arch. Microbiol. 152:115-118.

Chalupowicz, L., Barash, I., Reuven, M., Dror, O., Sharabani, G., Gartemann, K. H., Eichenlaub, R., Sessa, G., and Manulis-Sasson, S. 2017. Differential contribution of Clavibacter michiganensis ssp. michiganensis virulence factors to systemic and local infection in tomato. Mol. Plant Pathol. 18:336-346.

Chalupowicz, L., Cohen-Kandli, M., Dror, O., Eichenlaub, R. Gartemann, K. H., Sessa, G., Barash, I., and Manulis-Sasson, S. 2010. Sequential expression of bacterial virulence and plant defense genes during infection of tomato with Clavibacter michiganensis subsp. michiganensis. Phytopathology 100:252-261.

Chen, W., Zhang, Y., Yeo, W. S., Bae, T., and Ji, Q. 2017. Rapid and efficient genome editing in Staphylococcus aureus by using an engineered CRISPR/Cas9 System. J. Am. Chem. Soc. 139:3790-3795.

Chen, X., Bai, K., Lyu, Q., Jiang, N., Li, J., and Luo, L. 2021. Role of penicillin-binding proteins in the viability, morphology, stress tolerance and pathogenicity of Clavibacter michiganensis. Phytopathology 111:1301-13012.

Daher, G. C., Harris, B. E., and Diasio, R. B. 1990. Metabolism of pyrimidine analogues and their nucleosides. Pharmacol. Ther. 48:189222.

Danielsen, S., Kilstrup, M., Barilla, K., Jochimsen, B., and Neuhard, J. 1992. Characterization of the Escherichia coli codBA operon encoding cytosine permease and cytosine deaminase. Mol. Microbiol. 6:1335-1344.

Davis, M. J., Gillaspie, A. G., Vidaver, A. K., and Harris, R. W. 1984. Clavibacter: A new genus containing some phytopathogenic coryneform bacteria, including Clavibacter xyli subsp. xyli sp. nov., subsp. nov. and Clavibacter xyli subsp. cynodontis subsp. nov. pathogens that cause ratoon stunting disease of sugarcane and bermudagrass stunting disease. Int. J. Syst. Evol. Microbiol. 34:107-117.

Dreier, J., Meletzus, D., and Eichenlaub, R. 1997. Characterization of the plasmid encoded virulence region pat-1 of phytopathogenic Clavibacter michiganensis subsp. michiganensis. Mol. Plant-Microbe Interact. 10:195-206.
Dubois, V., Arpin, C., Dupart, V., Scavelli, A., Coulange, L., André, C., Fischer, I., Grobost, F., Brochet, J. P., Lagrange, I., Dutilh, B., Jullin, J., Noury, P., Larribet, G., and Quentin, C. 2008. Beta-lactam and aminoglycoside resistance rates and mechanisms among Pseudomonas aeruginosa in French general practice (community and private healthcare centres). J. Antimicrob. Chemother. 62:316-323.

Garneau, J. E., Dupuis, M. E., Villion, M., Romero, D. A., Barrangou, R., Boyaval, P., Fremaux, C., Horvath, P., Magadán, A. H., and Moineau, S. 2010. The CRISPR/Cas bacterial immune system cleaves bacteriophage and plasmid DNA. Nature 468:67-71.

Greco, O., and Dachs, G. U. 2001. Gene directed enzyme/prodrug therapy of cancer: Historical appraisal and future prospectives. J. Cell. Physiol. 187:22-36.

Grissa, I., Vergnaud, G., and Pourcel, C. 2007a. The CRISPRdb database and tools to display CRISPRs and to generate dictionaries of spacers and repeats. BMC Bioinf. 8:172.

Grissa, I., Vergnaud, G., and Pourcel, C. 2007b. CRISPRFinder: A web tool to identify clustered regularly interspaced short palindromic repeats. Nucleic Acids Res. 35:W52-W57.

Grissa, I., Vergnaud, G., and Pourcel, C. 2008. CRISPRcompar: A website to compare clustered regularly interspaced short palindromic repeats. Nucleic Acids Res. 36:W145-W148.

Horvath, P., and Barrangou, R. 2010. CRISPR/Cas, the immune system of bacteria and archaea. Science 327:167-170.

Huang, H., Zheng, G., Jiang, W., Hu, H., and Lu, Y. 2015. One-step highefficiency CRISPR/Cas9-mediated genome editing in Streptomyces. Acta Biochim. Biophys. Sin. (Shanghai) 47:231-243.

Hughes, L. E., Beck, D. A., and O'Donovan, G. A. 2005. Pathways of pyrimidine salvage in Streptomyces. Curr. Microbiol. 50:8-10.

Hwang, I. S., Oh, E. J., Lee, H. B., and Oh, C. S. 2019. Functional characterization of two cellulase genes in the Gram-positive pathogenic bacterium Clavibacter michiganensis for wilting in tomato. Mol. Plant-Microbe Interact. 32:491-501.

Jahr, H., Dreier, J., Meletzus, D., Bahro, R., and Eichenlaub, R. 2000 The endo-beta-1,4-glucanase CelA of Clavibacter michiganensis subsp. michiganensis is a pathogenicity determinant required for induction of bacterial wilt of tomato. Mol. Plant-Microbe Interact. 13: 703-714.

Jiang, N., Lv, Q. Y., Xu, X., Cao, Y. S., Walcott, R. R., Li, J. Q., and Luo, L. X. 2016. Induction of the viable but nonculturable state in Clavibacter michiganensis subsp. michiganensis and in planta resuscitation of the cells on tomato seedlings. Plant Pathol. 65:826-836.

Jiang, W., Bikard, D., Cox, D., Zhang, F., and Marraffini, L. A. 2013. RNA-guided editing of bacterial genomes using CRISPR-Cas systems. Nat. Biotechnol. 31:233-239.

Jiang, Y., Chen, B., Duan, C., Sun, B., Yang, J., and Yang, S. 2015. Multigene editing in the Escherichia coli genome via the CRISPR-Cas9 system. Appl. Environ. Microbiol. 81:2506-2514.

Jiang, Y., Qian, F., Yang, J., Liu, Y., Dong, F., Xu, C., Sun, B., Chen, B., Xu, X., Li, Y., Wang, R., and Yang, S. 2017. CRISPR-Cpf1 assisted genome editing of Corynebacterium glutamicum. Nat. Commun. 8: 15179 .

Jinek, M., Chylinski, K., Fonfara, I., Hauer, M., Doudna, J. A., and Charpentier, E. 2012. A programmable dual-RNA-guided DNA endonuclease in adaptive bacterial immunity. Science 337:816-821.

Kaup, O., Gräfen, I., Zellermann, E.-M., Eichenlaub, R., and Gartemann, K.-H. 2005. Identification of a tomatinase in the tomato-pathogenic actinomycete Clavibacter michiganensis subsp. michiganensis NCPPB382. Mol. Plant-Microbe Interact. 18:1090-1098.

Kirchner, O., Gartemann, K. H., Zellermann, E. M., Eichenlaub, R., and Burger, A. 2001. A highly efficient transposon mutagenesis system for the tomato pathogen Clavibacter michiganensis subsp. michiganensis. Mol. Plant-Microbe Interact. 14:1312-1318.

Laine, M. J., Nakhei, H., Dreier, J., Lehtilä, K., Meletzus, D., Eichenlaub, R., and Metzler, M. C. 1996. Stable transformation of the gram-positive phytopathogenic bacterium Clavibacter michiganensis subsp. sepedonicus with several cloning vectors. Appl. Environ. Microbiol. 62:1500-1506.

Larson, M. H., Gilbert, L. A., Wang, X., Lim, W. A., Weissman, J. S., and Qi, L. S. 2013. CRISPR interference (CRISPRi) for sequencespecific control of gene expression. Nat. Protoc. 8:2180-2196.

Leenay, R. T., Maksimchuk, K. R., Slotkowski, R. A., Agrawal, R. N., Gomaa, A. A., Briner, A. E., Barrangou, R., and Beisel, C. L. 2016. Identifying and visualizing functional PAM diversity across CRISPRCas systems. Mol. Cell 62:137-147.

Li, K., Cai, D., Wang, Z., He, Z., and Chen, S. 2018. Development of an efficient genome editing tool in Bacillus licheniformis using CRISPRCas9 nickase. Appl. Environ. Microbiol. 84:e02608-17. 
Liu, J., Wang, Y., Lu, Y., Zheng, P., Sun, J., and Ma, Y. 2017. Development of a CRISPR/Cas9 genome editing toolbox for Corynebacterium glutamicum. Microb. Cell Fact. 16:205.

Loyse, A., Dromer, F., Day, J., Lortholary, O., and Harrison, T. S. 2013. Flucytosine and cryptococcosis: Time to urgently address the worldwide accessibility of a 50-year-old antifungal. J. Antimicrob. Chemother. 68:2435-2444.

Lyu, Q., Bai, K., Kan, Y., Jiang, N., Thapa, S. P., Coaker, G., Li, J., and Luo, L. 2019. Variation in streptomycin resistance mechanisms in Clavibacter michiganensis. Phytopathology 109:1849-1858.

Marraffini, L. A. 2015. CRISPR-Cas immunity in prokaryotes. Nature 526:55-61.

McManus, P. S., Stockwell, V. O., Sundin, G. W., and Jones, A. L. 2002. Antibiotic use in plant agriculture. Annu. Rev. Phytopathol. 40:443-465.

Meletzus, D., Bermphol, A., Dreier, J., and Eichenlaub, R. 1993. Evidence for plasmid-encoded virulence factors in the phytopathogenic bacterium Clavibacter michiganensis subsp. michiganensis NCPPB382. J. Bacteriol. 175:2131-2136.

Meletzus, D., and Eichenlaub, R. 1991. Transformation of the phytopathogenic bacterium Clavibacter michiganense subsp. michiganense by electroporation and development of a cloning vector. J. Bacteriol. 173: 184-190.

Mohanraju, P., Makarova, K. S., Zetsche, B., Zhang, F., Koonin, E. V., and van der Oost, J. 2016. Diverse evolutionary roots and mechanistic variations of the CRISPR-Cas systems. Science 353:aad5147.

Mojica, F. J. M., Díez-Villaseñor, C., García-Martínez, J., and Almendros, C. 2009. Short motif sequences determine the targets of the prokaryotic CRISPR defence system. Microbiol. Read. 155:733-740.

Ren, C., Liu, Y., Guo, Y., Duan, W., Fan, P., Li, S., and Liang, Z. 2021. Optimizing the CRISPR/Cas9 system for genome editing in grape by using grape promoters. Hortic. Res. 8:52.

Rezzoagli, C., Wilson, D., Weigert, M., Wyder, S., and Kümmerli, R. 2018. Probing the evolutionary robustness of two repurposed drugs targeting iron uptake in Pseudomonas aeruginosa. Evol. Med. Public Health 2018:246-259.

Savory, E. A., Weisberg, A. J., Stevens, D. M., Creason, A. L., Fuller, S. L., Pearce, E. M., and Chang, J. H. 2020. Phytopathogenic Rhodococcus have diverse plasmids with few conserved virulence functions. Front. Microbiol. 11:1022.

Shalem, O., Sanjana, N. E., Hartenian, E., Shi, X., Scott, D. A., Mikkelson, T., Heckl, D., Ebert, B. L., Root, D. E., Doench, J. G., and Zhang, F. 2014. Genome-scale CRISPR-Cas 9 knockout screening in human cells. Science 343:84-87.
Stork, I., Gartemann, K. H., Burger, A., and Eichenlaub, R. 2008. A family of serine proteases of Clavibacter michiganensis subsp. michiganensis: chpC plays a role in colonization of the host plant tomato. Mol. Plant Pathol. 9:599-608.

van der Geize, R., de Jong, W., Hessels, G. I., Grommen, A. W., Jacobs, A. A., and Dijkhuizen, L. 2008. A novel method to generate unmarked gene deletions in the intracellular pathogen Rhodococcus equi using 5-fluorocytosine conditional lethality. Nucleic Acids Res. 36:e151.

van der Oost, J., Jore, M. M., Westra, E. R., Lundgren, M., and Brouns, S. J. 2009. CRISPR-based adaptive and heritable immunity in prokaryotes. Trends Biochem. Sci. 34:401-407.

Vliegenthart, J., Ketelaar-van Gaalen, P., and van de Klundert, J. 1991. Nucleotide sequence of the aac 33 gene, a gentamicin resistance determinant encoding aminoglycoside-(3)-N-acetyltransferase III expressed in Pseudomonas aeruginosa but not in Escherichia coli. Antimicrob. Agents Chemother. 35:892-897.

Whitman, W., Goodfellow, M., Kämpfer, P., Busse, H.-J., Trujillo, M., Ludwig, W., Suzuki, K.-i., and Parte, A., eds. 2012. Bergey's Manual of Systematic Bacteriology: Volume 5: the Actinobacteria. SpringerVerlag, New York, NY, U.S.A.

Xing, L., Sun, X., Deng, X., Kotedia, K., Urano, M., Koutcher, J. A., Ling, C. C., and Li, G. C. 2009. Expression of the bifunctional suicide gene CDUPRT increases radiosensitization and bystander effect of 5-FC in prostate cancer cells. Radiother. Oncol. 92:345-352.

Yan, M. Y., Yan, H. Q., Ren, G. X., Zhao, J. P., Guo, X. P., and Sun, Y. C. 2017. CRISPR-Cas12a-assisted recombineering in bacteria. Appl. Environ. Microbiol. 83:e0947-17.

Zhang, K., Duan, X., and Wu, J. 2016. Multigene disruption in undomesticated Bacillus subtilis ATCC 6051a using the CRISPR/Cas9 system. Sci. Rep. 6:27943.

Zhang, Y., Chen, Y., Zhu, X., Xu, Y., Hou, Y., Gao, T., and Zhou, M. 2011. A molecular mechanism of resistance to streptomycin in Xanthomonas oryzae pv. oryzicola. Phytoparasitica 39:393-401.

Zhang, Z., Mao, Y., Ha, S., Liu, W., Botella, J. R., and Zhu, J. K. 2016. A multiplex CRISPR/Cas9 platform for fast and efficient editing of multiple genes in Arabidopsis. Plant Cell Rep. 35:1519-1533.

Zhao, D., Yuan, S., Xiong, B., Sun, H., Ye, L., Li, J., Zhang, X., and Bi, C. 2016. Development of a fast and easy method for Escherichia coli genome editing with CRISPR/Cas9. Microb. Cell Fact. 15:205.

Zong, Y., Wang, Y., Li, C., Zhang, R., Chen, K., Ran, Y., Qiu, J. L., Wang, D., and Gao, C. 2017. Precise base editing in rice, wheat and maize with a Cas9-cytidine deaminase fusion. Nat. Biotechnol. 35: 438-440. 